\title{
Decision-Making Method on the Degree of Lecturers' Compliance to Job Titles
}

\author{
Natalia P. Putivtseva \\ Belgorod State University \\ Belgorod, Russia \\ putivzeva@bsu.edu.ru \\ Olga P. Pusnaya \\ Belgorod State University \\ Belgorod, Russia \\ pusnaya@bsu.edu.ru
}

\author{
Tatiana V. Zaitseva \\ Belgorod State University \\ Belgorod, Russia \\ zaitseva@bsu.edu.ru \\ Maria A. Petina \\ Belgorod State University \\ Belgorod, Russia \\ petina_m@bsu.edu.ru
}

\author{
Elena V. Kaludgnaya \\ Belgorod State University \\ Belgorod, Russia \\ kaludgnaya@bsu.edu.ru
}

\begin{abstract}
A university lecturer conducting educational and scientific activities in the technical and IT spheres should have a high level of personal and professional competencies, including social and psychological, pedagogical, methodological, and scientific competencies. The article proposes an approach to the lecturer selection process, consisting of a hierarchical model of lecturer competencies, criteria for assessing private competencies, assessment and selection methods, selection algorithms, software, and hardware assessment and selection tools, which allows assessing various professional and personal competencies of lecturers and making decisions about the degree of their compliance.
\end{abstract}

Keywords - competencies, hierarchical model, criteria for assessing private competencies, assessment and selection methods, selection algorithms.

\section{INTRODUCTION}

An analysis of literary sources has shown that researchers are currently studying various aspects of the formation and assessment of professional qualities and competencies of lecturers of educational institutions. Examples of aspects are $[1,3,6]$ :

- psychological foundations for modeling professional competence of a lecturer,

- criteria for the effectiveness of lecturers and the formation of pedagogical competence of lecturers of educational institutions,

- professional competence of lecturers,

- methodologies for assessing the activities of lecturers of higher educational institutions,
- requirements for lecturer qualifications and assessment of the quality of teaching staff,

- organizational and pedagogical system for assessing the pedagogical activity of university lecturers, etc.

Nevertheless, modern approaches to assessing the competencies of lecturers have a number of drawbacks, including significant ones, such as the subjectivity of making a final decision, the inability to apply the methodology under changed conditions, solving narrow, particular problems, and the refusal to use methods of modern decision theory $[1,2,3]$. In this regard, decisions made in universities often turn out to be insufficiently substantiated and may cause distrust of interested parties.

\section{Problem Statement}

A university lecturer conducting educational and scientific activities in the technical and IT fields should have a high level of personal and professional competencies. To assess the quality of lecturers is not enough to evaluate only their personal competencies. Professional competencies also play an important role, since this area is actively developing. And for the university in order to train competitive specialists in this subject area, who are able to adapt to changing conditions quickly and the emergence of new technologies and software and hardware, the level of professional competencies of the teaching staff (TS) should be quite high.

Considering that the activity of a lecturer of a higher school is multifunctional and includes not only pedagogical, but also research, methodological, technical and didactic and other types of activity, it is advisable to separate professional and personal competencies. In this case, pedagogical competence, including educational subject, to consider as an 
integral part of the professional. In addition, since training and education require direct communication with students, the application of methods of psychological influence on them, methods of self-regulation of mental states, etc., it is advisable to use a broader concept - the "socio-psychological, pedagogical competence" of a higher school lecturer.

\section{METHODOLOGY}

As part of the study, a lecturer competency model will be developed as a set of particular characteristics, and methods and methods for their assessment will be determined. These particular characteristics are of varying degrees of importance for the professional activities of the lecturer, including those related to the specialization of the lecturer.

Within the framework of the study, the baseline data will be collected to evaluate each lecturer in an educational institution, and private competencies and characteristics will be selected to evaluate lecturer competencies within the framework of the developed model. The formalization of the evaluation criteria for each qualification characteristic will also be carried out, methods for assessing the important factors of the criteria will be selected, gradations for each selected private characteristic of the lecturer's competencies will be developed to make appropriate managerial decisions, and a decision-making method will be developed to the degree to which the lecturer corresponds to the job title.

\section{LITERATURE REVIEW}

In practice, different methods are used to evaluate the professional activities of lecturers (state certification, portfolio assessment, competitive selection, etc.) [4]. Known dissertation research related to the quantitative assessment of the work of lecturers, their activities, professional qualities, and professionalism, etc. An analysis of the sources shows that these approaches do not allow the models proposed in them to be adapted to the changed application conditions, and attach great importance to subjective expert assessments, taking little account of more formalized methods, and use estimation algorithms that are inappropriate with respect to competence, etc. [1]

Issues of multicriteria assessment are the subject of research by a number of foreign and Russian researchers [2, 5-9]. In order to characterize the lecturer as a qualified specialist, it is necessary to indicate specific properties, the presence of which the object allows one to make an appropriate judgment.

There are a number of approaches to assessing lecturers. For example, the Assessment Center involves a comprehensive assessment of lecturers by competency, taking into account the personal and professional qualities of specific lecturers [10].

Biysk Technological Institute uses its own methodology, within the framework of which a system of indicators of the lecturer's work is distinguished [11]: educational, educational and methodological, research, organizational and methodological work, as well as advanced training and social educational activities. To assess the activities of the lecturer, a point system is used with weighting coefficients, the values of which are set for each section, each integral and private indicator of the sections, with the involvement of experts. The calculation of the number of points scored by the lecturer is carried out by summing up the points scored for all private indicators, which, using weight coefficients, are folded into integral indicators. Scores for activities (sections) are formed from the well-targeted sums of integral indicators.

The Moscow Automobile and Road Institute uses a different approach [12]. The rating of each lecturer consists of two parts: rating "P", which characterizes the accumulated qualification potential, and rating "A", reflecting its current activity in the main areas of activity. An absolute personal rating is calculated as the well-targeted sum of the ratings " $\mathrm{A}$ " and " $\mathrm{P}$ ".

In addition to the fact that a number of higher education institutions use different approaches to determining the rating of lecturers, many researchers interpret the concept and content of the concepts used for assessing professional and personal competencies in different ways [3, 4]. Some researchers limit themselves to considering only the personal competencies of a higher education lecturer, while others suggest combining them with professional ones [1, 13].

The considered approaches are not entirely suitable for assessing all the components of the competencies of a university lecturer who, in addition to teaching, is engaged in scientific and methodological work, and the authors do not consider these aspects of the lecturer's activity practically.

Based on the foregoing, we can conclude that at present there is no methodology that allows one to take into account the multidimensionality of activities fully, taking into account their unequal preference, depending on the lecturer's job title.

\section{DISCUSSION}

Based on a review of the literary sources and publications of researchers, an analysis was made of existing approaches and distinguished groups of competencies, on the one hand, so that they could fully cover all aspects of the activity, and there was no mutual intersection between them. All types of competencies were divided into 2 groups - personal (PC) and professional (PrC). Professional and methodological (MC) and scientific (SC) competencies are a combination of three components: sets of relevant socio-psychological and pedagogical (RSPC), methodological (MC) and scientific (SC) competencies. Each of the many sets of competencies is proposed to be evaluated using tests, surveys, as well as various documentary sources.

Figure 1 presents an algorithm of making a decision on the degree of compliance of lecturers' job titles. 


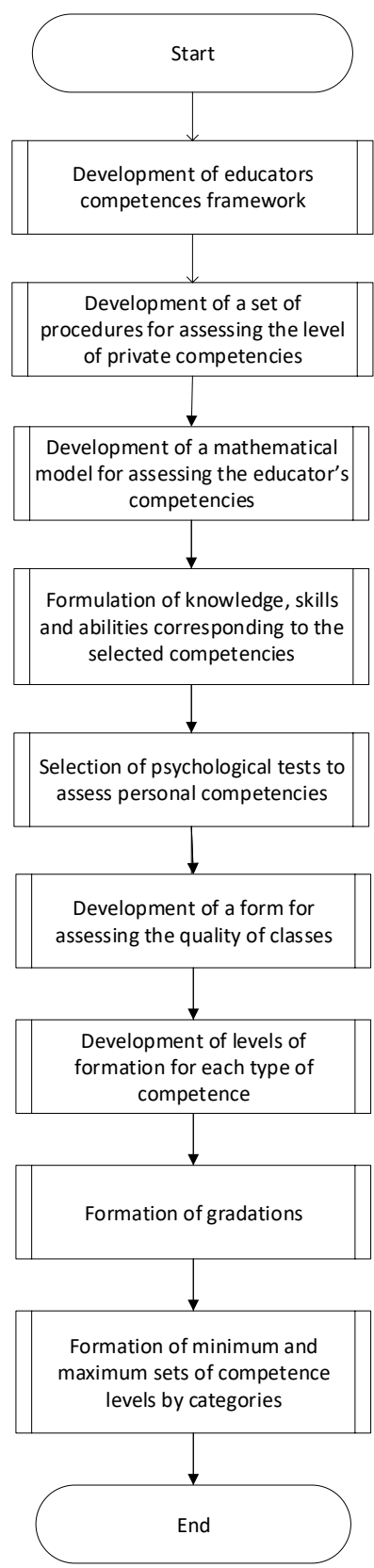

Fig. 1. Algorithm of making decision on the degree of compliance of lecturers' job titles

Each of the sets of competencies can be represented by a set of private competencies with a vector representing a list of those psychodiagnostic and / or praximetric methods that are used to evaluate existing private competencies (Figure 2).

The integrated assessment of the competencies formation $\mathrm{CF}$ is calculated as a well-targeted sum of private competencies, taking into account their probability of using the appropriate methods in the assessment procedure.

The disadvantage of this model is that it does not take into account the levels of formation of each group of competencies, as well as the positions of the assessed lecturers. To assess the achievements they use the minimum values for the level.

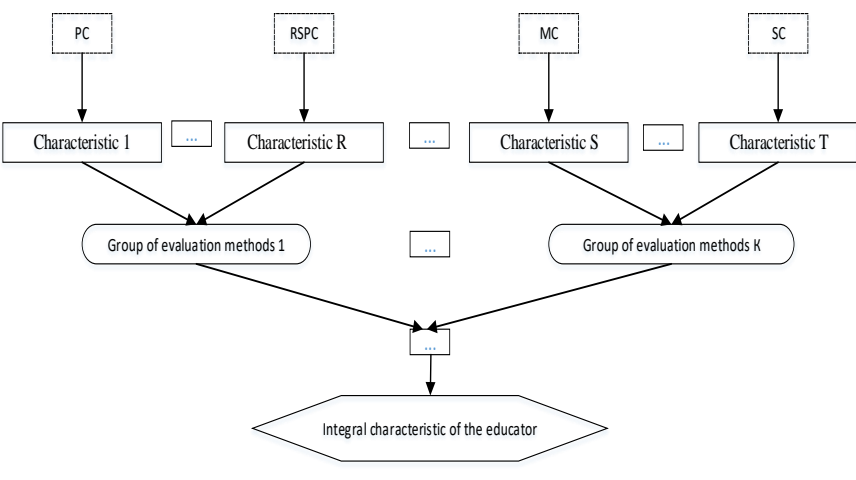

Fig. 2. Integral characteristics of the lecturer

In this connection, the levels of competency formation by groups and minimum sets by faculty categories were developed:

Assistant $=\{$ PC: satisfactory, RSPC: reproductive, MC: reproductive, $\mathrm{SC}$ : reproductive $\}$

Senior Lecturer $=\{$ PC: satisfactory, RSPC: conceptual, $\mathrm{MC}$ : conceptual, SC: reproductive $\}$

Associate Professor $=\{\mathrm{PC}$ : medium, RSPC: productive, MC: productive, SC: conceptual $\}$

Professor $=\{\mathrm{PC}$ : average, $\mathrm{RSPC}$ : productive, $\mathrm{MC}$ : productive, SC: productive $\}$

For a visual presentation, we also give the maximum sets in the corresponding categories:

Assistant: $\{$ PC: above average, RSPC: productive, MC: productive, SC: conceptual $\}$

Senior Lecturer: $\{\mathrm{PC}$ : above average, RSPC: productive, MC: integrative, $\mathrm{SC}$ : productive $\}$

Associate Professor: \{PC: above average, RSPC: integrative, $\mathrm{MC}$ : integrative, $\mathrm{SC}$ : integrative $\}$

Professor: $\{\mathrm{PC}$ : above average, RSPC: integrative, MC: integrative, SC: integrative $\}$

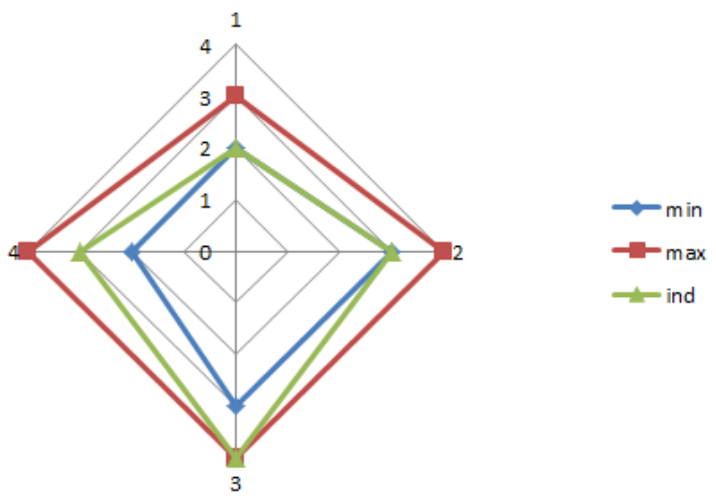

Fig. 3. Web model for associate professor

Figure 3 presents a web model that reflects the minimum and maximum sets of levels of competencies for an assistant professor. 


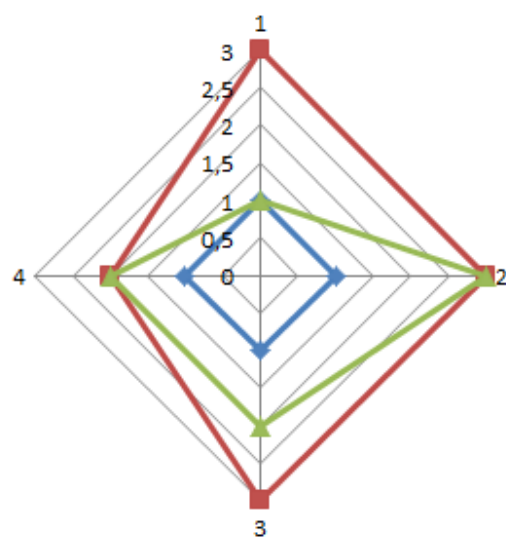

Fig. 4. Web model for associate

Figure 4 presents a web model that reflects the minimum and maximum sets of levels of competencies for an assistant.

\section{RESULTS}

As part of the work, an experiment was conducted to identify the lecturer's compliance with the position based on the proposed methodology.

The primary results obtained during the assessment procedure for the two selected lecturers (applying for reelection as an associate professor) correspond to the following competency levels:

For the first candidate: PC: 16 (middle level), RSPC: 38 (productive level), MC: 26 (productive level), SC: 31 (productive level);

For the second candidate: PC: 21 (above average), RSPC: 32 (productive level), MC: 39 (integrative level), SC: 28 (productive level)

The obtained values of private competencies for candidates were compared with the previously proposed cobweb model (Figure 5).

Based on the calculations, we can conclude that each of the lecturers meets the requirements of Belorussian State University when re-election to a vacant post, as well as the values of his competence indicators proposed in the developed methodology, are within the limits sufficient for his reapproval in the corresponding position. In the event that these are two teachers applying for the same position, preference should be given to Lecturer 2, since the values of his personal and methodological competencies are at a higher level.

The proposed model for assessing the quality of a university lecturer is workable and claims to be more reasonable than the currently used documentation model, but requires verification on a larger sample of teachers applying for vacant positions.

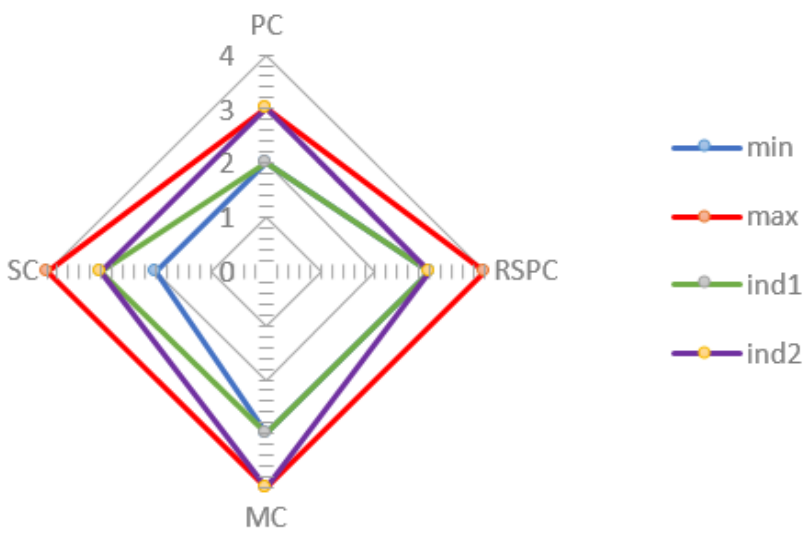

Fig. 5. Web models of two candidates for the position of assistant professor

\section{References}

[1] G.A. Ignatieva, The expert activity in education, N. Novgorod Nizhegorodskiy gumanitarnyy tsentr, 2003, pp. 28-34.

[2] O.I. Larichev, Theory and decision-making methods, as well as the Chronicle of events in the Magic countries: A textbook for university students, Moscow: Logos, 2002, pp. 92-107.

[3] N.V. Tretyakova, "Assessment of the quality of the teacher's work based on the methodology of multivariate analysis of his activity", Uchenyye zapiski universiteta imeni P.F. Lesgafta, vol. 11(81), pp. 151-155, December 2011.

[4] V.D. Shadrikov, I.V. Kuznetsova, "Forming professional competencies", Spravochnik zamestitelya direktora shkoly, vol. 10, pp. 64-70, October 2012

[5] E.G. Zhilyakov, "Adaptive determination of the relative importance of objects based on high-quality pairwise comparisons", Economics and Mathematical Methods, vol. 42(2), pp. 111-122, April 2006.

[6] S.V. Gutsykova Expert judgment method: Theory and practice, Moscow: Institut psikhologii RAN, 2011, pp. 7-45.

[7] V.D. Nogin, Decision making in a multi-criteria environment: quantitative approach, Moscow: FIZMATLIT, 2002, pp. 14-18.

[8] A.B. Petrovsky, Theory of decision making, Moscow: Publishing Center "Academy", 2009, pp. 203-221.

[9] T.L. Saaty, The Analytic Hierarchy Process, New York: McGraw-Hill, 1980, pp. 206-230.

[10] S.V. Burmistrov, S.A. Tikhonovskova, S.I. Samygin, "Assessment center as a new technology in the personnel management system", Humanities, social-economic and social sciences, vol. 6-7, July 2017.

[11] V.P. Erdakova, G.V. Leonov, V.A. Kharitonov, A.G. Ovcharenko, "Quality management system BTI ALTSTU: from development to certification", Garantii kachestva vysshego professionalnogo obrazovaniya, pp. 289-291, April 2008 [International research and practical conference, p. 360, 2008].

[12] G.G. Kulikov, K.A. Konev, V.A. Suvorova, G.V. Startsev, "Formation of criteria indicators for the automated calculation and monitoring of the teacher rating in a single information space of the department", Vestnik UGATU, vol. 4(39), pp. 175-184, April 2010.

[13] S.N. Begidova, "Modern requirements for the professional activity of a teacher", Vestnik Adygeyskogo gosudarstvennogo universiteta, vol. 1(193), pp. 15-19, 2017. 